\title{
The use of information technology in assessing the health of human capital as a factor of environmental justice and sustainable development
}

\author{
Anastasia Bashkireva $^{1, *}$, Tatyana Bashkireva $^{2}$, Alexander Morozov ${ }^{3}$, Tamara Shchelina $^{4}$ \\ and Olga Vereykina ${ }^{5}$ \\ ${ }^{1}$ Faculty of Physical Education and Sports, Russian State University named after S.A. Yesenin, \\ 390000 Ryazan, Russia \\ ${ }^{2}$ Institute of Psychology, Pedagogy and Social Work, Russian State University named after S.A. \\ Yesenin, 390000 Ryazan, Russia \\ ${ }^{3}$ Research Center, The Federal State Institution "Research Institute of the of the Federal penitentiary \\ service of Russia”, 125130, Moscow, Russia \\ ${ }^{4}$ Department of General Pedagogy and Pedagogy of Vocational Education, Russian State University \\ named after S.A. Yesenin, 390000 Ryazan, Russia \\ ${ }^{5}$ Faculty of Physical Education and Sports, Arzamas Branch of the Federal State Autonomous \\ Educational Institution of Higher Education "N.I. Lobachevsky National Research Nizhny Novgorod \\ State University ", 607200 Arzamas, Russia
}

\begin{abstract}
The cumulative nature of various types of xenobiotics and pollutants requires long-term comprehensive environmental protection measures, including in the territories of the petrochemical industry. Due to its high sensitivity, the child's body is a "marker" of hypersensitivity to xenobiotics. The article clarifies the concept of "environmental justice". The essence of its use lies in the ethical organization of the ecological environment. As safe as possible for the health of every person and the biosphere as a whole. The use of information technologies can use to monitor and correct the health of children and adults at the regional level, taking into account the characteristics of the ethnic group and their adaptive-compensatory reactions.
\end{abstract}

\section{Relevance}

The instability of socio-economic development leads to various risks, including environmental ones. A person is actively introduced to the world around him and changes it. There is a violation of the biosphere under the influence of an anthropogenic factor. In the natural environment, xenobiotics and pollutants of various origins accumulate, which are zones of ecological risk $[15 ; 28 ; 30]$. The health of children and students living in areas of environmental risk is of particular concern. Caring for the safety of children health begins at birth and covers the entire period of development and maturation. The WHO

\footnotetext{
* Corresponding author: bashkireva32@gmail.com
} 
Declaration on Health, Environment and Climate Change [29] emphasize the need to stimulate and enhance the exchange of experiences and practices that improve public health.

The Council of the World Health Organization (WHO), in the aspect of sustainable development, proposed a new conception - "Health for All" [14]. The implementation of the principle of "health for all" implies increased funding. That will improve the quality of life. Financial resources must be distributed equitably and ensure lasting positive change in people's lives. Therefore, the primary investment of the world community should be in the health of the younger generation in a safe environment [26]. In recent years for sustainable development, the environmental policy years have focused on ensuring environmental justice [31]. Environmental justice can be a guarantor of the safety of life and health of people who live in the area of environmental risk.

The concept of "environmental justice" appeared in the United States in the early 1980s. The conception of "environmental justice" is the protection of the environment, ensuring the health of all people, regardless of their origin, social status, religion, socio-economic level of the country [15]. Other researchers consider this concept a constructive environmental policy aimed at equitable distribution of environmental risks and ensuring social security of the world community [8; 25].

Sources of environmental problems are industrial production, which has technical devices that pollute and destroy ecological systems. Unfortunately, the extraction, processing and production of goods for the global industry and daily demand lead to environmental pollution due to imperfect technological processes. To attainment sustainable development, it is necessary to eliminate the imperfection of processing. It leads to social, regional conflicts [6]. The world community is in favour of resolving these conflicts. To solution environmental conflicts, it is necessary to change people's views on environmental education from the point of view of environmental ethics [13].

Researchers believe that it is necessary to create such mechanisms of environmental management that would ensure the safety of the health of the local population in the area of environmental risk $[10 ; 12]$. It noted that the concept of human security criticizing. It is due to the collision of three global problems: 1) extraction and production of products necessary for the life support of society; 2) provision of jobs to labour resources; 3) safety of public health [7].

In recent years, the area of knowledge that studies human functioning in the biosphere has been intensively developing. Consider from the standpoint of the interaction of the anthroposystem with the habitat, called "human ecology". Human ecology is an interdisciplinary science and includes components: biological and social, applied ("man society - environment"). At the beginning of the new millennium, an ecological doctrine was formulated in the field of health care, education and culture [17-18; 22].

Our work aims to analyze the health of human capital as a factor in environmental justice and sustainable development using information technology.

\section{Methodology}

The article uses the analysis of literary sources, which contain the concept of "environmental justice". We studied the documents: WHO, Environmental Protection Agency (EPA) and other sources. According to EPA, it is necessary to strengthen the scientific basis for decision-making aimed at environmental justice. It needs to develop:

- methods for assessing adverse and cumulative risks;

- innovative monitoring technologies and technological solutions to environmental problems;

- promoting the sustainability of the development of society and the safety of its health. 
In empirical studies used the indicators of heart rate variability. We investigate boys and girls living in the territory of ecological risk (conditionally safe for health). The examination was carried out by a non-invasive method using the hardware-software complex "Varicard" in statistical processing "ISCIM 6.0". In the analysis, we used the wellknown indicators of spectral analysis of heart rate variability what makes the possibility to analyze the mechanisms of heart rate control.

In recent years, the introduction of information, including digital solutions, in the sphere of ecology notes. Own empirical research has made it possible to develop criteria for the health of human capital, which are significant to the development of information technologies for monitoring health in areas of environmental risks. It is essential for the implementation of environmental justice in the workforce and future workforce.

\section{Results and discussion}

In modern society, the industrial development of extreme territories is expanding new technologies are being introduced into the industry. In these conditions of human life, it is significant to study the adaptation of various groups to environmental change under the influence of social factors. Today, the study of the health and adaptation of indigenous and alien ethnic groups to natural and climatic and specific environmental conditions is acquiring particular relevance.

In psychophysiological and physiological reactions, the basis is an adaptation, and pathological ones - compensation. The compensatory response carried out by changing the functional connections between systems of the organism rebuilds its structural relation, compensating for the insufficiency of functions and life support systems.

In recent years, in world studies, much attention paid to the territories where oil refineries and petrochemical plants are located $[1-3 ; 5]$. It is in these territories that the likelihood of developing a malignant pathology is high. It is due to the content of chromium, benzene in the air and the total concentration of soot.

For Russian cities saturated with industrial enterprises, the following substances are priority: sulfur dioxide, carbon monoxide, nitrogen oxides, carbon disulfide, gasoline, hydrogen sulfide, phenol, xylene, styrene, benzene, ethylbenzene, manganese, trivalent chromium, ammonia, lead and its compounds. These compounds are carcinogenic: benzpyrene, formaldehyde, chromium and its compounds, cadmium, soot, chlorinated hydrocarbons, acetaldehyde, nickel, arsenic, epichlorohydrin, propylene oxide, acrylonitrile.

The results of monitoring the state of the environment and its impact on the health of the population: correlations between morbidity and the environment (including the state of the air basin in many cities) revealed. Air pollution is one of the leading factors affecting the state of mental, psychological and social health. It is especially true for a growing organism $[9 ; 11 ; 21]$.

The global ecological crisis has changed the relationship between man and nature. The human body, especially the child, is inextricably linked with the environment, with the geochemical components of the Earth and the geophysical characteristics of the Universe. Interaction and interdependence of these factors provide:

- homeostasis;

- stabilization of adaptive regulatory systems;

- preservation of mental, physical, psychological, social health [23].

Health indicators at the population level are fertility, child health, genetic polymorphism, population adaptability to climatic and geographical conditions, readiness to perform various functions, and others. 
Children are sensitive to chemical, biological and radiation pollution of the environment. It is due to morphological and functional immaturity. Therefore, anthropogenic environmental pollutants pose a particular danger to children. It is common knowledge that if schools take place in areas of environmental risks, then the children health can suffer from pollutants, worsening their academic performance and school attendance [24]. Analysis of literature sources has shown that the educational success of schoolchildren depends on environmental justice, disease prevention, and a healthy and safe environment [27].

We have carried out to study health in terms of heart rate variability in boys and girls who live in the territory of environmental risks (conditionally safe for health). Let us give an example of some of the individual indicators of the health of young men. Studies have shown that the stress of functional systems is significantly higher in young men living in areas hazardous to health $(t=4.06 ; \mathrm{P}<0.001)$. Synchronization of heart rhythm control in young men living in the territory of environmental risks carried out by the respiratory centre. This mechanism ensures the adaptation processes of the body of young men to the extreme environmental conditions of their place of residence. A young man living in territories that are conditionally safe for health shows harmonious synchronization of adaptive reactions (Fig.1).

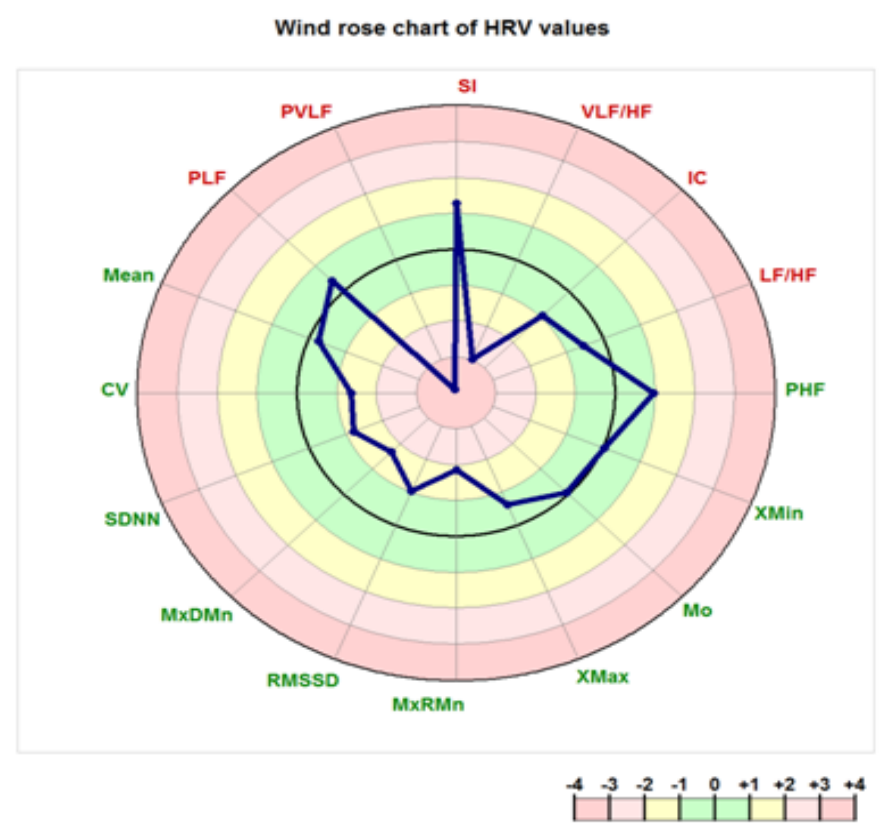

A 


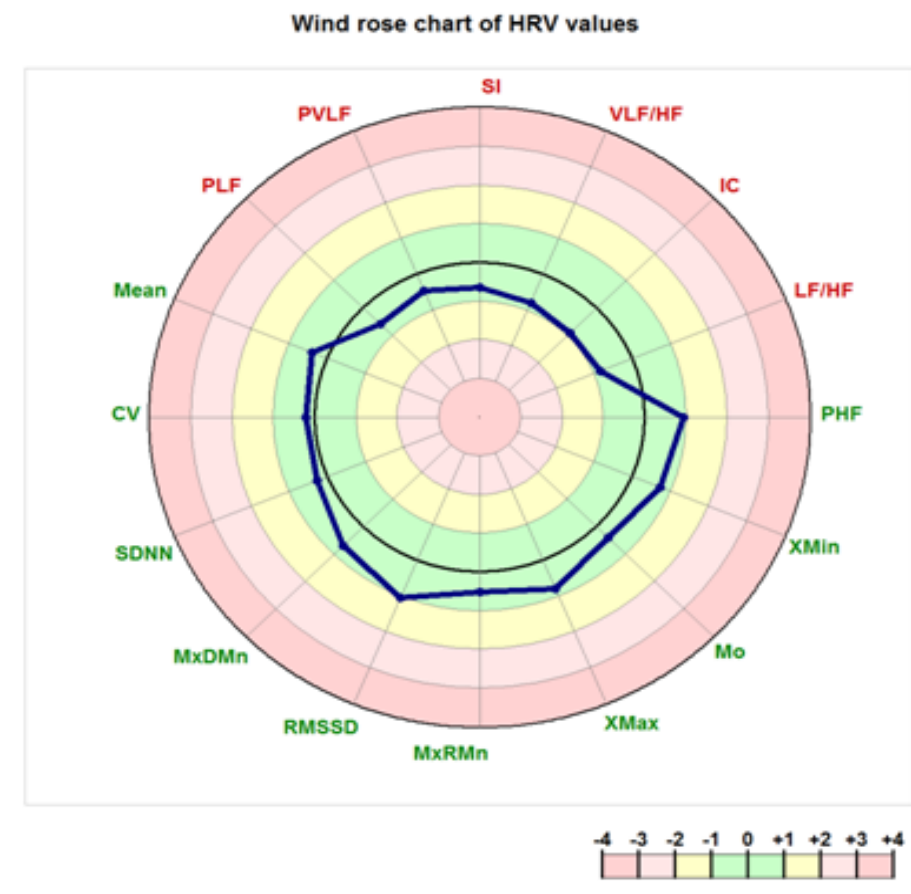

B

Fig. 1. Indicators of heart rate variability among young men living in the territory of ecological risk (A) and conditionally safe for health (B).

Note: green colour - the functional state is correct; yellow - voltage of systems; red - failure of adaptation systems.

The reactions of both the adult and the child are not the same to unfavourable factors. Some people (with hypersensitivity) feel the mutagenic and teratogenic effects of factors of the external environment (at very low doses). Even under the influence of the natural background radiation of the Earth. Due to its high sensitivity, the child's body is a "marker" of hypersensitivity to xenobiotics. Possession of this kind of information allows you to monitor, model, and correct the health of children, youth, adults at the regional and state levels, taking into account the characteristics of the ethnic group and their adaptivecompensatory reactions.

The cumulative nature of various types of xenobiotics and pollutants requires long-term comprehensive environmental protection measures. It is impossible to achieve an effective result in a short time. The younger generation is under the pressure of anthropogenic factors hazardous to health. For this, biorhythmological monitoring of people health (mental, psychological, social) should also be carried out.

On November 2, 2021, the Environmental Protection Agency (EPA) proposed standards that will reduce the emission of methane and other harmful substances in the oil and gas industry [13]. When establishing environmental quality standards, using the indicators, control over which ensured using appropriate measurement techniques (methods), indication and testing methods. They must be taken into account when developing information technologies for monitoring environmental information that would reflect the 
level of health of human capital, including those living in the territories of environmental risks [19-20].

Even though in recent years, control over the state of the environment has increased, safe technologies introducing into production though there is a problem of monitoring environmental risks. Unfortunately, the introduction of innovative technologies is not widespread and of high quality.

Literary sources note that a small number of digital solutions in the field of ecology introduced, for example, online measurements of air and water quality [4]. In this regard, there is a need to develop, using information technologies, a model for monitoring and assessing public health based on environmental indicators in the territories of environmental risks. Society should implement environmental justice for the workforce today as well as for the future workforce. To organize the safest ecological environment for them.

The use of information technology affects (indirectly):

- to create extended information;

- control and management of the safety of human health.

The European Commission (2019) has paid particular attention to the creation of digital technologies in agriculture. Digital technologies send at creating healthy, environmentally friendly products, zero environmental pollution without toxic substances.

\section{Conclusion}

Thus, the analysis of literary sources showed that a significant factor in the sustainable development of society is the resolution of environmental conflicts on the understanding of the importance of the health of human capital as a factor of environmental justice. The analysis of literature sources allowed us to clarify the concept of "environmental justice". From our point of view, environmental justice lies in the ethical organization of the ecological environment. This environment should be as safe as possible for the health of each person and the biosphere.

Among the general health criteria developed by us, it is advisable to dwell on those that allow us to assess the health of human capital using information technologies, the resource of which is digitalization. These criteria are:

1. the incidence of child populations as a marker of the state of the environment;

2. sanitary and epidemiological problems;

3. the state of the environment (environmental information);

4. the functional state and adaptation of the inhabitants of specific territories.

The significant point in any research is the establishment of synchronization between the influencing factor and the reaction of objects to them. Needs to pay attention to weak effects, the relationship of which is not always distinct and synchronized. Currently, the solution to these problems is associated with society's awareness of the importance of environmental ethics, the development and use of information technologies to assess the health of human capital as a factor in environmental justice and sustainable development.

\section{References}

1. A. K. Ahmadov, Oil, democracy, and context Comparat, Politic. Stud, 47, 1238-1267 (2014)

2. E. Arond, A. Bebbington, J. L. Dammert, NGOs as innovators in extractive industry governance. Insights from the EITI process in Colombia and Peru Extract, Ind. Soc, 6, 665-674 (2019) 
3. M. Conde, P. Le Billon, Why do some communities resist mining projects while others do not? Extract. Ind. Soc., 4, 681-697 (2017)

4. M. A. Cottrell, O. A. Galea, S. P. O'Leary, A. J. Hill, T. G. Russell, Real-time telerehabilitation for the treatment of musculoskeletal conditions is effective and comparable to standard practice: a systematic review and meta-analysis, ClinRehabil, 31, 625-638 (2017)

5. C. Coumans, Minding the "Governance Gaps": re-thinking conceptualizations of host state "Weak Governance" and Re-focussing on home state governance to prevent and remedy harm by multinational mining companies and their subsidiaries, Extract. Ind. Soc., 6, 675-687 (2019)

6. D. Ikazaki, A Human Capital Based Growth Model with Environment and Corruption, Journal of Economic Structures, 3, 10 (2014). Access mode: https://journalofeconomicstructures.springeropen.com/articles/10.1186/s40008-014$\underline{0010-3}$

7. N. Engwicht, J. Grabek, A human security perspective on natural resource governance: what makes reforms effective? South African J. Int. Affairs, 26, 185-207 (2019)

8. R. Sandler, P. C. Pezzullo, Environmental Justice and Environmentalism (The MIT Press, 2007)

9. S. Gephine, O. Le Rouzic, F. Machuron, B. Wallaert, C. Chenivesse, D. Saey, F. Maltais, P. Mucci, J. M. Grosbois, Long-Term Effectiveness of a Home-Based Pulmonary Rehabilitation in Older People with Chronic Obstructive Pulmonary Disease: A Retrospective Study, Int J Chron Obstruct Pulmon Dis, 15, 2505-2514 (2020)

10. J. M. Grosbois, A. Gicquello, C. Langlois, O. Le Rouzic, F. Bart, B. Wallaert, C. Chenivesse, Long-term evaluation of home-based pulmonary rehabilitation in patients with COPD, Int J Chron Obstruct Pulmon Dis, 10, 2037-2044 (2015)

11. J.-M. Grosbois, S. Gephine, O.L. Rouzic, C. Chenivesse, Feasibility, safety and effectiveness of remote pulmonary rehabilitation during COVID-19 pandemic, Respiratory Medicine and Research (2021). Access mode: https://doi.org/10.1016/j.resmer.2021.100846

12. H. Xiao, J. You, The Heterogeneous Impacts of Human Capital on Green Total Factor Productivity: Regional Diversity Perspective, Front. Environ. Sci (2021). Access mode: https://www.frontiersin.org/articles/10.3389/fenvs.2021.713562/full

13. A. Heruyono, H. Herdiansyah and L. G. S. Putri, Environmental ethics perspective in fostering environmental awareness in the bandung eco-camp community, IOP Conf. Ser.: Earth Environ. Sci., 802, 012050 (2021)

14. Environmental Justice, EPA (2021). Access mode: https://www.epa.gov/environmentaljustice

15. Top economists call for radical redirection of the economy to put Health for All at the centre in the run-up to G20, WHO (2021). Access mode: https://www.who.int/news/item/26-10-2021-top-economists-call-for-radicalredirection-of-the-economy-to-put-health-for-all-at-the-centre-in-the-run-up-to-g20

16. J. Schilling, A. Schilling-Vacaflor, R. Flemmer, R. Froese, The Extractive Industries and Society, The Extractive Industries and Society Available, 100826 (2020). Access mode: $\underline{\text { https://doi.org/10.1016/j.exis.2020.10.009 }}$ 
17. J. Lan, A. Munro, Environmental Compliance and Human Capital: Evidence from Chinese Industrial Firms, National Graduate Institute for Policy Studies 7-22-1 Roppongi, Minato-ku (2012)

18. J. G. Zivin, M. Neidell, Environment, Health, and Human Capital, Journal of Economic Literature, 51 (3), 689-730 (2013). Access mode: https://www.jstor.org/stable/23644825

19. K. Kilova, T. Kitova, P. Kasnakova, Telemedicine in help of rehabilitation in the conditions of COVID-19, Health Policy and Technology, 10 (2), 100508 (2021). Access mode: https://doi.org/10.1016/j.hlpt.2021.100508

20. L. Knox, M. Dunning, C. A. Davies, R. Mills-Bennet, T. W. Sion, K. Phipps, V. Stevenson, C. Hurlin, K. Lewis, Safety, feasibility, and effectiveness of virtual pulmonary rehabilitation in the real world, Int J Chron Obstruct Pulmon Dis, 14, 775780 (2019)

21. L. Kolbe, A. Jaywant, A. Gupta, W. M. Vanderlind, G. Jabbour, Use of virtual reality in the inpatient rehabilitation of COVID-19 patients, General Hospital Psychiatry, 71, 76-81 (2021)

22. C. S. Kruse, N. Krowski, B. Rodriguez, L. Tran, J. Vela, M. Brooks, Telehealth and patient satisfaction: a systematic review and narrative analysis, BMJ Open, 7 (8), 016242 (2017)

23. E. Lara, F. F. Caballero, L. A. Rico-Uribe, B. Olaya, J. M. Haro, J. L. Ayuso-Mateos, et al. Are loneliness and social isolation associated with cognitive decline? Int $\mathrm{J}$ Geriatr Psychiatry, 34 (11) 1613-1622 (2019). Access mode: http://doi.org/10.1002/gps.5174

24. M. D. Galea, Telemedicine in rehabilitation, Phys Med RehabilClin N Am, 30, 473483 (2019)

25. B. McCloskey, A. Zumla, G. Ippolito, et al., Mass gathering events and reducing further global spread of COVID-19: a political and public health dilemma, Lancet, 395 (10230), 1096-1099 (2020)

26. G. T. Miller, Environmental science: working with the Earth (1931)

27. Ministerial Declaration on "Health, Environment and Climate Change" (2021). Access mode: https://www.who.int/globalchange/mediacentre/events/Ministerial-declarationEN.pdf

28. C. M. Nolan, D. Kaliaraju, S.E. Jones, S. Patel, R. Barker, J.A. Walsh, S. Wynne, W. Man, Home versus outpatient pulmonary rehabilitation in COPD: a propensitymatched cohort study, Thorax, 74(10), 996-998 (2019)

29. M. Taylor, Climate change, relational vulnerability and human security: rethinking sustainable adaptation in agrarian environments, Climate Dev., 5, 318-327 (2013)

30. World health organization (WHO). Access mode: https://www.who.int/ru/news/item/10-01-2018-un-environment-and-who-agree-tomajor-collaboration-on-environmental-health-risks

31. M. Fleurbaey, S. Kartha, Sustainable Development and Equithttps (2021). Access mode: www.ipcc.ch/site/assets/uploads/2018/02/ipcc_wg3 ar5_chapter4.pdfy 